\title{
Opinions of pregnant women regarding desire and choice of labour companion
}

\begin{abstract}
Introduction: Labour and delivery are considered as periods of extreme anxiety, fear and stress in women's life. Women need physical and psychological support to withstand stress. Having a labour companion provides multiple benefits and is recommended by World Health Organization. The objective of the study was to seek opinions of pregnant women regarding their desire and choice of labour companion, so that labour room policy can be changed in favour of allowing labour companion.
\end{abstract}

Material and methods: A questionnaire based cross sectional study was carried out at Pravara Rural Hospital, Loni, Ahmednagar over a period of 2 months. Two hundred women in early labour were interviewed using a pretested and validated questionnaire. Information on socio cultural aspects, obstetric history and their desire and choice of labour companion was collected and analysed.

Results: Majority of the women belonged to middle and lower socio economic class, in the age group below 25 years, were less educated and had early marriages. Fifty percent were Primigravid as and seventy percent were registered cases. Ninety percent women expressed their desire to have labour companion. Fifty percent chose mother as first choice to be the labour companion.Ten percent did not wish to have a labour companion. Most common reasons for choosing a labour companion was for psychological support (42\%), reduction of labour pains(21\%), reduction of fear and apprehension( $12 \%)$, feeling of strength and encouragement (7\%) and to have a smooth delivery process.

Conclusion: Study revealed a strong desire by pregnant women in labour for having a labour companion. Mother was the first choice to be the labour companion. Women expressed that labour companion will give them support, will lessen their trouble, pain and apprehension, will give them extra power and strength to withstand the labour stress. All maternity hospitals should reconsider their policies in favour of allowing labour companion.

Keywords: labour companion, labour room policy, maternal morbidity, respectful maternity care, physical and mental abuse of women in labour
Volume 7 Issue 4 - 2018

\author{
Vidyadhar Bangal,' Vanashri Bayaskar,'2 \\ Ashwini Arjun, ${ }^{3}$ Irfana Khan, ${ }^{4}$ Ujwala Thorat ${ }^{5}$ \\ 'Department of Obstetrics and Gynaecology, Pravara Institute \\ of Medical Sciences, India \\ ${ }^{2}$ Pravara Rural Hospital, India \\ ${ }^{3,4}$ Ashwin Ayurved Medical College, India \\ ${ }^{5}$ Pravara Institute of Medical Sciences, India
}

Correspondence: Vidyadhar Bangal, Department of Obstetrics and Gynaecology, Rural Medical College, Pravara Institute of Medical Sciences, India, Tel 9145154778, Email vbb217@rediffmail.com

Received: June II, 2018 | Published: August 23, 2018

\section{Introduction}

Labour and delivery are considered as periods of extreme anxiety, fear and stress in women's life. ${ }^{1}$ Women need physical and psychological support to withstand labour and delivery related stress. Having a labour companion, provides multiple benefits and is been recommended by World Health Organization. ${ }^{2}$ Research has consistently demonstrated that women greatly value and benefit from the presence of someone they trust during labour and childbirth to provide emotional, psychological and practical support and advice. ${ }^{2}$ Allowing and supporting the presence of a woman's companion of choice during labour and childbirth is an effective intervention that is respectful of women's autonomy and agency and can be an important aspect of improving quality of care during labour and childbirth. ${ }^{2}$ Continuous support for a labouring woman by a lay person or a professional is a well-evaluated intervention. Large randomised controlled trials have been carried out all over the world and these have shown positive pregnancy outcomes for mother and baby..$^{2-5}$ The supported woman is more likely to give birth without using analgesia, less likely to have a caesarean delivery or instrumental vaginal birth and less likely to report dissatisfaction with her childbirth experience. ${ }^{3-7}$ In spite of the overwhelming evidence of benefit when a labouring woman receives continuous support from a lay person, implementation of the intervention sometimes meets resistance, particularly from healthcare providers working in maternity units. ${ }^{7,8}$ This resistance is present even at the facilities, where there is staff scarcity or where epidural analgesia is not available-that is, situations where companions would be of benefit or comfort to a labouring woman. Other than fears of introducing infection and other harm, cultural factors have also been the source of this resistance even among the potential beneficiaries. ${ }^{7,8}$ Presently, there is a policy of not allowing any labour companion at Pravara Rural hospital for the above mentioned reasons. The objective of the study was to seek opinions of pregnant women regarding their desire and choice of labour companion, so that labour room policy can be changed in favour of allowing labour companion.

\section{Material and methods}

A cross sectional study was carried out for a period of two months (March and April 2018) at Pravara Rural Hospital, which is attached to a Rural Medical College in Ahmednagar district in Maharashtra. Approximately $9000-10,000$ deliveries take place in the hospital per year, of which 3000-3500 deliveries are by caesarean 
section. Most of the women belong to lower middle and lower socio economic class and have education up to $10-12$ class. They belong to nearby villages. The average age at marriage is $18-20$ years and average family size is $2-2.2$ children per family. The institutional delivery rate is approximately $90-95$ percent. The complete 4 visit antenatal coverage is around 75-80percent among the women who avail delivery services in the hospital. Majority of deliveries (over 90 percent) are conducted by doctors (postgraduate students and faculty members) and remaining 10 percent by trained nurses. In India, there is no cadre of "midwives", as that of western world, who have primary responsibility of conducting normal deliveries. The caesarean section rate at the hospital is around 30 percent. Very few instrumental deliveries (less than 0.5 percent) are carried out in the hospital. There was no practice of allowing labour companion in the labour room, when the present study was carried out. The study was questionnaire based and social worker and doctors graduated in Ayurvedic Medicine conducted the interview of women in early labour. Written informed consent was obtained from pregnant women, who were interviewed in the study. Women in active labour and who had associated medical and or obstetrical complications were excluded from the study. Women of all age groups, in latent phase of labour, irrespective of their parity were included in the study. A pretested and validated short questionnaire was used to collect the information from two hundred women in labour regarding their socio-demographic profile, level of education, willingness, opinion and preference of labour companion. The questions were simple, specific and few, thus interview could be finished in ten minutes. It did not cause any discomfort to the respondent. In this study, we used the term 'labour companionship' to describe support provided to a woman during labour but not during childbirth. The gathered information was transferred to excel sheet .The relevant data was compiled, tabulated and interpreted to draw conclusions.

\section{Observations and results}

Two hundred pregnant women were interviewed in the labour room by three researchers over a period of two months. All participants cooperated well in the interview process. Average time for each interview was less than 10 minutes. Presently, the labour ward of Pravara Rural Hospital does not allow any labour companion. This protocol is been followed since the inception of the hospital, i.e since 40years. There have been various instances and occasions, where in female relative of the labouring woman was required to stay with the woman in labour. Main reasons for calling relative inside the labour room were un co-operative behaviour of pregnant woman, woman trying to run out of labour ward due to fear. These women were either less educated or uneducated, from lower socio economic class, unbooked, primi gravidas, who had not been exposed to hospital environment any time in the past or they were mentally unstable or mentally challenged. It was observed that the study participants were mainly young women (82\%), below the age of 25years (Table 1). Assessment of level of education of the respondents revealed that, $10 \%$ were illiterate and $81 \%$ were educated up to 10 th class (Table 2).The women had early marriages at the age of 18-20 years. Most of the participants were home makers and had no much experience of the world beyond their villages (Table 3 ). Their life was mainly confined to the villages, where they were residing. More than two third $(69 \%)$ women were non-booked with the hospital and had directly reported to labour room during labour (Table 4). Half the numbers of participants were primi para and maximum number of participants had parity below three (97\%) (Table 5). Women belonged mainly to middle socio economic class (72\%)or lower class (28\%) (Table 6). Significant percentage of women $(90 \%)$ expressed desire to have labour companion (Table 7). Out of all multi-parous women, $64 \%$ did not have any labour companion in their previous delivery (Table 8 ). Mother was the first choice (54\%) to be the labour companion for highest number of women, followed by other female relative (Table 9). Eight percent of women expressed desire for their spouse to be the labour companion. Ten percent of women did not want any labour companion. Women during interview narrated various reasons in favour of labour companion. Most common reasons for choosing a labour companion was for psychological support (42\%), reduction of labour pain(21\%), reduction of fear and apprehension(12\%), feeling of strength and encouragement $(7 \%)$ and to have a smooth delivery process (Table 10). It was observed that $77 \%$ of women were accompanied by either mother or mother in law. Remaining women were accompanied by sister or sister in law, grandmother or aunt. In only $5 \%$ cases spouse of the woman was available at the time of the delivery (Table 11).

Table I Distribution of women as per age

\begin{tabular}{lll}
\hline Sr. No & Age group & Number of women $(\%)(n=200)$ \\
\hline 1 & $<20$ year & $30(15)$ \\
2 & $20-25$ year & $134(67)$ \\
3 & $26-30$ year & $30(15)$ \\
4 & $>30$ year & $6(3)$ \\
\hline
\end{tabular}

Table 2 Distribution of women as per Education

\begin{tabular}{lll}
\hline Sr. No & Education & Number of women $(\%)(n=200)$ \\
\hline 1 & Illiterate & $20(10)$ \\
2 & Primary & $60(30)$ \\
3 & Secondary & $86(38)$ \\
4 & Higher secondary & $26(13)$ \\
5 & Graduation & $18(9)$ \\
\hline
\end{tabular}

Table 3 Distribution of women as per occupation

\begin{tabular}{lll}
\hline Sr. No & Occupation & Number of women $(\%)(\mathbf{n = 2 0 0 )}$ \\
\hline I & Home maker & $186(93)$ \\
2 & Farmer & $6(3)$ \\
3 & Service & $2(1)$ \\
4 & Shopkeeper & $4(2)$ \\
5 & Labourer & $2(1)$ \\
\hline
\end{tabular}

Table 4 Distribution of women as per booked status

\begin{tabular}{lll}
\hline Sr. No & Status & Number of women $(\%)(n=200)$ \\
\hline 1 & Booked & $138(69)$ \\
2 & Not-booked & $62(3 \mathrm{I})$ \\
\hline
\end{tabular}

Table 5 Distribution of women as per parity

\begin{tabular}{lll}
\hline Sr. No & Parity & Number of women $(\%)(n=200)$ \\
\hline$I$ & Nullipara & $100(50)$ \\
\hline
\end{tabular}


Table Continued

\begin{tabular}{lll}
\hline Sr. No & Parity & Number of women $(\%)(n=200)$ \\
\hline 2 & Primipara & $58(29)$ \\
3 & Second para & $34(17)$ \\
4 & Third para & $4(2)$ \\
5 & $\begin{array}{l}\text { Fourth para } \\
\text { and above }\end{array}$ & $4(2)$ \\
\hline
\end{tabular}

Table 6 Distribution of women as per socio economic class

\begin{tabular}{|c|c|c|}
\hline $\begin{array}{l}\text { Sr. } \\
\text { No }\end{array}$ & Socio economic class & $\begin{array}{l}\text { Number of women (\%) } \\
(n=200)\end{array}$ \\
\hline I & Upper class & $0(0)$ \\
\hline 2 & Middle class & I44(72) \\
\hline 3 & Lower class & $56(28)$ \\
\hline $\begin{array}{l}\text { Sr. } \\
\text { No }\end{array}$ & $\begin{array}{l}\text { Desire for labour } \\
\text { companion }\end{array}$ & $\begin{array}{l}\text { Number of women }(\%) \\
(n=200)\end{array}$ \\
\hline 1 & Yes & $180(90)$ \\
\hline 2 & No & $20(10)$ \\
\hline
\end{tabular}

Table 8 Distribution of women as per labour companion in last delivery

\begin{tabular}{lll}
$\begin{array}{l}\text { Sr. } \\
\text { No }\end{array}$ & $\begin{array}{l}\text { Labour companion in } \\
\text { last delivery }\end{array}$ & Number of women $(\%)(\mathbf{n}=100)$ \\
\hline I & Yes & $36(36)$ \\
2 & No & $64(64)$ \\
\hline
\end{tabular}

Table 9 Distribution of women as per choice of labour companion

\begin{tabular}{lll}
\hline $\begin{array}{l}\text { Sr. } \\
\text { No }\end{array}$ & Choice of labour companion & $\begin{array}{l}\text { Number of women (\%) } \\
(\mathbf{n = 2 0 0 )}\end{array}$ \\
\hline 1 & Mother & $108(54)$ \\
2 & Mother In law & $16(8)$ \\
3 & Sister / Sister In law & $16(8)$ \\
4 & Aunty & $8(4)$ \\
5 & Spouse & $16(8)$ \\
6 & Any other & $16(8)$ \\
7 & No companion & $20(10)$ \\
\hline
\end{tabular}

Table 10 Distribution of women as per opinions about labour companion

\begin{tabular}{|c|c|c|}
\hline $\begin{array}{l}\text { Sr. } \\
\text { No }\end{array}$ & Opinions & $\begin{array}{l}\text { Number of women } \\
(\%)(n=200)\end{array}$ \\
\hline I & $\begin{array}{l}\text { Will Feel support/psychological support/ } \\
\text { encouragement/get love and care }\end{array}$ & $84(42)$ \\
\hline 2 & Will feel less trouble/pain & $42(21)$ \\
\hline 3 & Will feel comfortable/feel good & $26(13)$ \\
\hline 4 & $\begin{array}{l}\text { Will have less fear/Less apprehension/ } \\
\text { Less stress }\end{array}$ & $24(12)$ \\
\hline 5 & $\begin{array}{l}\text { Will get power /strength to withstand } \\
\text { stress }\end{array}$ & $14(07)$ \\
\hline 6 & $\begin{array}{l}\text { Will not feel lonely/less apprehension } \\
\text { about outcome/delivery will be proper }\end{array}$ & $6(03)$ \\
\hline
\end{tabular}

\begin{tabular}{|c|c|c|}
\hline $\begin{array}{l}\text { Sr. } \\
\text { No }\end{array}$ & Opinions & $\begin{array}{l}\text { Number of women } \\
(\%)(n=200)\end{array}$ \\
\hline 7 & $\begin{array}{l}\text { Had lots of trouble last time, need } \\
\text { someone this time/will not trouble } \\
\text { anyone, if mother is there/want someone } \\
\text {, just like that }\end{array}$ & $4(02)$ \\
\hline
\end{tabular}

Table I I Distribution of women as per accompanying person in labour

\begin{tabular}{lll}
\hline Sr. No & Accompanying person & $\%$ of women $(\mathbf{n}=\mathbf{2 0 0})$ \\
\hline 1 & Mother & 60 \\
2 & Mother In law & 17 \\
3 & Sister / Sister In law & 9 \\
4 & Spouse & 5 \\
5 & Grand Mother & 4 \\
6 & Aunty & 3 \\
7 & Any Other & 2 \\
\hline
\end{tabular}

\section{Discussion}

In last few years, there has been significant rise in number of deliveries at Pravara Rural Hospital.At times, the labour room is so busy that it is not possible to pay adequate individual attention to every woman in labour.The number of doctors and nurses are not enough to look after the needs of individual labouring woman. It was thought that introducing labour companion will have multiple advantages that include physical and psychological support to the woman in labour ,assistance to nurses in catering to the comfort and other needs of women in labour ,better understanding of the labour difficulties by near ones, that arise in

labour process, better communication between labouring woman, her companion and other relatives waiting outside the labour room or at home, less likely hood of allegations by the relatives regarding suboptimum care, less need of labour analgesia, less chances of abusive behaviour by health care providers. The reasons for not allowing labour companion at Pravara Rural hospital were risk of introduction of infection and the inconvenience caused by movement of too many people in the labour room. It was also thought that labouring woman get different sets of instructions from the companion and thus create a confused state of mind and labouring woman throw tantrums in presence of relative. At times, the presence of forced companion may not have smooth relationship with the labouring woman, thus counter producing the effects. ${ }^{1}$ The health care providers felt a pressure of satisfying the individual women's demands in the presence of her labour companion. ${ }^{1}$ They also have apprehension about the wrong messages being delivered to other relatives about the minor errors or deficiencies in care of the woman in labour. There is also a matter of concern about the pictures and audio video recordings of labour room happenings by labour companion and using that information in possible litigation case. The privacy of other women is also hampered in presence of too many unknown persons moving in the labour room, unless there are enough provisions of maintaining the privacy. The literature review and the guidelines by the World Health Organization on the subject prompted to conduct the study to find out the opinions of women in labour about their desire and choice of labour companion in the present study.

Childbirth is a stressful physical and psychological experience. 
According to the fear-tension-pain cycle, ${ }^{9}$ excessive anxiety increases endogenous release of catecholamine and thus reduces blood flow to and from the placenta, restricts fetal oxygen supply, reduces the effectiveness of uterine contractions, and slows labour progress. ${ }^{10} \mathrm{It}$ is thought that adequate support to women in labour may result in shorter duration of labour and a higher level of maternal satisfaction. There are cultural differences in the provision of support during childbirth. In the US and the UK, husbands, partners or close relatives are the main supporters during labour. In addition, a doula, a labour companion specialist, is advocated to guide effective support. In many other countries, they are excluded from the delivery room, and companionship during labour is uncommon. In Hong Kong, has been advocated for the past decade. ${ }^{11}$ In India, some hospitals allow women relatives are allowed to stay with the women in labour, while in some, it is not allowed. In some corporate hospitals, the women relative and the husband are allowed in first stage of labour, while husband is asked to wait outside the delivery suit in second stage of labour. The relatives are invariable kept out of the operation theatre, if woman is delivered by caesarean section. In western world, husband of the woman in labour is allowed to be with her even in caesarean section and he stands in close proximity to anaesthesiologist at head end. Women have traditionally been attended by a companion in labour mainly in domiciliary deliveries, but initiatives to increase the number of women giving birth in health facilities have not necessarily respected this tradition, as many of the institutions do not allow a labour companion. A Cochrane effectiveness review by Hodnett and colleagues concluded that having a labour companion improves outcomes for women, yet this basic, inexpensive intervention is far from universal ${ }^{3}$. The presence of a labour companion is therefore regarded as an important aspect of improving quality of care during labour and childbirth. In the Hodnett review, continuous support is defined as "continuous presence and support during labor and birth. The person providing the support could have qualifications as a healthcare professional (nurse, midwife) or training as a doula or childbirth educator, or be a family member, spouse/partner, friend or stranger with little or no special training in labor support". ${ }^{3}$

In a study conducted by Banda et al, majority (70.9\%) of the mothers wanted a supportive companion during labour, preferred someone they knew but the remainder said that they would be happy with anyone who offered companionship. The preferred companions were mother, sister, grandmother, aunt, mother-in-law, friend, male partner, anyone and midwife in order of frequency. Only $11.4 \%$ of the mothers wanted their male partner as a companion. ${ }^{1}$ Continuous support by a lay woman during labour and delivery facilitates birth, enhances the mother's memory of the experience, strengthens motherinfant bonding, increases breastfeeding success, and significantly reduces many forms of medical intervention, including caesarean delivery and the use of analgesia, anaesthesia, vacuum extraction, and forceps. ${ }^{12}$ In the present study, pregnant women expressed their opinions and desire about the labour companion. Large number of women expressed that with labour companion ,they will feel support/ psychological support/encouragement/get love and care(42\%), will experience less trouble/pain (21\%), will feel comfortable/feel good $(13 \%)$, will have less fear/less apprehension/less stress(12\%), will get power /strength to with stand stress(7\%), will not feel lonely/ less apprehension about outcome/delivery will be proper(3\%).Few women said that they had lots of trouble last time, need someone this time, need someone to accompany just like that (3\%).
Severe fear of childbirth complicates $6 \%$ to $10 \%$ of women in labour and is manifested as anxiety state, depression and bad dreams. ${ }^{13}$ In the present study, 12 percent of women in labour expressed that, they will experience less fear, if they are allowed to have a labour companion. Very often fear of childbirth leads to request for an elective caesarean section. In Finland, Sweden, and the United Kingdom, fear of childbirth or maternal request is the reason for about $7-22 \%$ of caesarean births..$^{13}$ In India around 10percent of caesarean sections are carried out on maternal request and the main reason for this demand is fear of labour pains and delivery process. Fear of childbirth is more common in nulliparous than in parous women. Due to tocophobia or fear of severe pain, some women run out of labour room and at times have wish to go home for delivery or insist for immediate caesarean section. Fear of labor pain is strongly associated with the fear of pain in general, and a previous complicated childbirth or inadequate pain relief are the most common reasons for requesting a CS among parous women. Fear of childbirth is not an isolated problem but associated with the woman's personal characteristics, mainly general anxiety, low self-esteem, and depression, and dissatisfaction with their partnership, and lack of support. Similar to other studies, a positive effect of companionship on maternal satisfaction was demonstrated through the opinions expressed by women in labour in the present study. Women expressed that they will have higher level of emotional support $(42 \%)$ and compassionate care, if some relative would be allowed to stay with them in labour. This indicates that the presence of a companion has a positive effect in maternal self-confidence and self-control during labour and birth. ${ }^{14}$

\section{Conclusion}

Study revealed a strong desire by pregnant women in labour for having a labour companion. Mother was the first choice to be the labour companion. Women expressed that labour companion will give them support, will lessen their trouble and pain and apprehension, will give them extra power and strength to withstand the labour stress. All maternity hospitals should reconsider their policies in favour of allowing labour companion.

\section{Acknowledgements}

None.

\section{Conflict of interest}

Author declares that there is no conflict of interest.

\section{References}

1. Banda G, Kafulafula G, Nyirenda E, et al. Acceptability and experience of supportive companionship during childbirth in Malawi. BJOG. 2010;117(8):937-945

2. Companion of choice during labour and childbirth for improved quality of care. 2016

3. Hodnett ED, Gates S, Hofmeyr GJ, et al. Continuous support for women during childbirth. Cochrane Database Syst Rev. 2007;CD003766.

4. Klaus MH, Kennell JH, Klaus PH. Mothering the Mother. How a Doula Can Help You Have a Shorter, Easier, and Healthier Birth. New York: Addison-Wesley Publishing Company; 1993.

5. Langer A. Continuous support for women during childbirth: RHL practical aspects. The WHO Reproductive Health Library. Geneva: World Health Organization; 2007. 
6. Labour companionship: every woman's choice. Video the WHO Reproductive Health Library, No 9. Oxford: Update Software Ltd; 2006.

7. Maimbolwa MC, Sikazwe N, Yamba B, et al. Views on involving a social support person during labour in Zambian maternities. J Midwifery Women's Health. 2001;46(4):226-234.

8. Dick-Read G. Childbirth without fear: The principles and practice of natural childbirth. UK: Pinter \& Martin Ltd; 2004.

9. Johnson RC, Slade P. Obstetric complications and anxiety during pregnancy: is there a relationship? J Psychosom Obstet Gynaecol. $2003 ; 24(1): 1-14$

10. Ip WY. Relationships between partner's support during labour and maternal outcomes. J Clin Nurs. 2000;9(2):265-272.

11. Pascali-Bonaro D, Kroeger M. Continuous female companionship during childbirth: a crucial resource in times of stress or calm. $J$ Midwifery Womens Health. 2004;49(4):19-27.

12. Saisto T, Halmesmäki E. Fear of childbirth: a neglected dilemma. Acta Obstet Gynecol Scand. 2003;82(3):201-208.

13. Bruggemann OM, Parpinelli MA, Osis MJ, et al. Support to woman by a companion of her choice during childbirth: a randomized controlled trial. Reprod Health. 2007;4:5.

14. Yuenyong S, O Brien B, Jirapeet V. Effects of labor support from close female relative on labor and maternal satisfaction in a Thai setting. $J$ Obstet Gynecol Neonatal Nurs. 2012;41(1):45-56. 